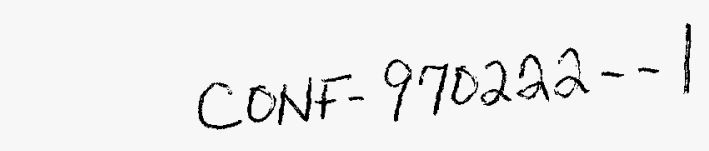

ENERGY DIVISION

DEFINING INTRA- AND INTERHOUR LOAD SWINGS

September 1996

Eric Hirst

Brendan Kirby

To be

sent for possible

publication in

IEEE Power Engineering

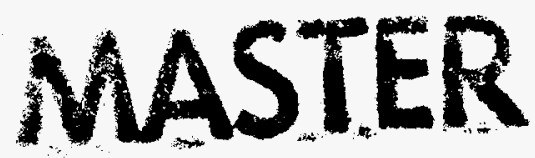

Prepared by the

OAK RIDGE NATIONAL LABORATORY

Oak Ridge, Tennessee 37831

managed by

LOCKHEED MARTIN ENERGY RESEARCH CORPORATION

for the

U.S. DEPARTMENT OF ENERGY

under contract DE-AC05-960R22464

"The submitted manuscript has been

authored by a contractor of the U.S.

Government under contract No. DE.

AC05-960R22464. Accordingly, the

U.S. Government retains a nonexclusive,

royalty-free license to publish or

reproduce the published form of this

contribution, or allow others to do so

for U.S. Government purposes." 


\section{DISCLAIMER}

This report was prepared as an account of work sponsored by an agency of the United States Government. Neither the United States Government nor any agency thereof, nor any of their employees, make any warranty, express or implied, or assumes any legal liability or responsibility for the accuracy, completeness, or usefulness of any information, apparatus, product, or process disclosed, or represents that its use would not infringe privately owned rights. Reference herein to any specific commercial product, process, or service by trade name, trademark, manufacturer, or otherwise does not necessarily constitute or imply its endorsement, recommendation, or favoring by the United States Government or any agency thereof. The views and opinions of authors expressed herein do not necessarily state or reflect those of the United States Government or any agency thereof. 


\section{DISCLAMMER}

Portions of this document may be illegible in electronic image products. Images are produced from the best available original document. 


\title{
DEFINING INTRA- AND INTERHOUR LOAD SWINGS
}

\author{
Eric Hirst and Brendan Kirby \\ Energy Division \\ Oak Ridge National Laboratory \\ Oak Ridge, TN 37831-6206
}

\begin{abstract}
Electricity consumption varies with time. These temporal variations include moment-to-moment fluctuations plus hour-to-hour changes associated with diurnal, weekly, and seasonal patterns. The problem naturally splits into two time frames: (1) fast fluctuations, on the order of seconds to minutes, and (2) slower fluctuations, on the order of an hour or longer. Fast fluctuations in aggregate load result primarily from the random movements of individual loads. Slower fluctuations result from common external causes, such as time of day, day of the week, and weather. This study empirically examines intra- and interhour load following. It develops methods to separate intra- and interhour load fluctuations, identifies the key features of each, and shows how they differ from each other.
\end{abstract}

\section{BACKGROUND}

The basic electrical services include generating capacity, energy supply, and power delivery (transmission). Ancillary services are needed to provide the basic electrical services, both to support transactions between buyers and sellers of electricity and to maintain reliability of the interconnected electrical grid. This paper examines the concepts and details associated with the function variously called load following, regulation, or regulation and frequency response; see [1] for additional details.

The concept of load following is widely understood; indeed, utilities have been providing this service for decades (1) to match generation to system load and (2) to maintain frequency within the interconnection close to $60 \mathrm{~Hz}$. However, the effort to unbundle generation services shows that the specifics of these services are often ambiguous. Separating fast fluctuations from longer-term load variations is important if the costs of these services are allocated to customers on the basis of their load-following requirements, and if the payments to generators reflect their contributions to meeting these needs.
We take an expansive view of this service, as illustrated by Fig. 1. The figure shows system load for a Midwestern control area from midnight to $3 \mathrm{a} . \mathrm{m}$. on a winter weekday morning. The total load consists of three components. The first element is the minimum constant (base) load during the period, about 9300 MW in this example. The second element is the trend during the hour and from hour to hour; here that element decreases monotonically from $800 \mathrm{MW}$ at midnight a.m. to $0 \mathrm{MW}$ at 3 a.m. The third element is the random fluctuations in load around the underlying trend; here the fluctuations range over $\pm 50 \mathrm{MW}$. This paper focuses on the second and third components.

The Federal Energy Regulatory Commission (FERC), in its final rule on open-access transmission, identified six ancillary services that transmission providers must offer to their customers [2]. FERC defines "regulation and frequency response" as the "extra generating capacity, called regulating margin, [required] to follow the moment-to-moment variations in the load located in a control area. Following load variations is necessary to maintain scheduled interconnection frequency at sixty cycles per second $(60 \mathrm{~Hz})$." FERC did not discuss interhour load following.

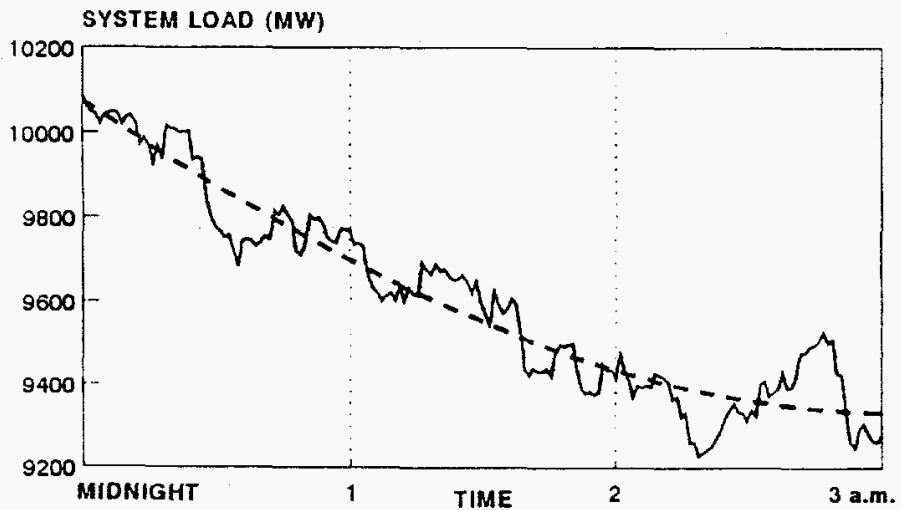

Fig. 1. Total load measured every minute for a Midwestern utility and a cubic fit to the data, from midnight to 3 a.m. 
In part because of the FERC rulemaking, the North American Electric Reliability Council (NERC) established an Interconnected Operations Services Working Group to develop an industry consensus on the definitions, requirements, obligations, and management for these services. The NERC working group identified two services relevant to this study: regulation and load following. Regulation was defined as the generating resources "used to balance supply resources with minute-to-minute load variations and to meet NERC control performance criteria" [3]. Unlike FERC, the working group separated the generator actions into two parts: (1) those associated with large frequency deviations [to which the generators respond through governor action and then in response to automatic-generation control (AGC) signals] and (2) those associated with the continuous regulation process (in response to AGC signals only). Large frequency deviations are caused by generation or transmission outages and occur rarely. Regulation is required continuously to balance generation and load. The working group also defined load following as the provision of generation capacity "to meet daily and hourly load variations" [4]. This service is intended to follow daily load cycles, in particular the morning pickup and afternoon dropoff that most utility systems experience.

A recent Oak Ridge National Laboratory report identified four components of load following [5]. The two control-area functions are maintenance of interconnection frequency at 60 $\mathrm{Hz}$ and maintenance of generation/load balance within the control area. These two functions are identical to what FERC calls "regulation and frequency response." The two customer functions include following the moment-to-moment fluctuations in loads (what the working group calls regulation) and following the longer-term (e.g., interhour) changes in load (what the working group calls load following). The two sets of functions are equivalent to each other. That is, if a control area completely and accurately meets the two customer functions, it will automatically meet its control-area responsibilities.

Neither the FERC nor the NERC nor the Oak Ridge discussions of ancillary services defined the appropriate time period over which to measure "moment-to-moment variations" in load, the speed with which load changes occur, or the amounts and ramp rates of generation needed to provide this service. None of these entities defined the boundaries between intra- and interhour load following, and none developed a suitable mechanism for extracting intrahour load-following patterns from load data.

Part of the confusion about these services invoives the time scales over which they are provided. Generators respond automatically (based on their inertia, governor control, impedance, and electrical proximity to the load) to fluctuations that occur faster than a second or two. Generators respond to slower fluctuations based on signals from the control-area operator's AGC system. The AGC system measures areacontrol error (ACE) every two to six seconds and sends signals to those generators that provide regulating service to increase or decrease output. Once every several minutes, the AGC system reoptimizes the generation dispatch to minimize operating costs. The control-area operator manually directs individual generators to ramp up and down over the course of an hour or more to track expected interhour load trends.

Thus, generator response to fast (less than a few seconds) fluctuations is automatic, based on the electrical properties of the generators and transmission system. Generator response to load fluctuations on the order of several seconds to several minutes, on the other hand, is managed by the AGC system in its effort to meet the NERC performance criteria. Generator response to longer-term load changes (several minutes to several hours) is based on manual directions and on the economic optimization of the AGC system. We might call the services that generators provide during these three time periods autonomous generator response, regulation, and load following.

The purpose of this paper is to examine empirically these intrahour and interhour load changes and the responses of a utility's generating resources to those load changes. We analyze data, primarily from one control area, to see how it maintains $\mathrm{ACE}$ close to zero in an effort to meet the $\mathrm{A} 1$ and $\mathrm{A} 2$ criteria. Overall, we estimate that load following costs U.S. electric utilities just over $\$ 1$ billion a year, equivalent to about 0.4 mills/kWh.

\section{COMPARING INTERHOUR AND INTRAHOUR LOAD SWINGS}

Total load, by definition, is equal to the sum of the intrahour load fluctuations, the interhour load changes, and the base load (which we assume to remain constant throughout an hour); see Fig. 1. Thus, the method used to define interhour load changes automatically determines the pattern of short-term load fluctuations.

We considered and analyzed several ways to identify the interhour load trends. These methods include the use of rolling averages over 10-, 30-, and 60-minute intervals and the use of linear, quadratic, and cubic regression models, each fit to three hours of data. (Fourier analysis can also be used to identify the frequency components of system load.) Table 1 shows that the rolling-average methods produce far too many sign changes in the interhour trend, compared with the six sign changes that the hourly data show for this day. Even the cubic and quadratic methods overestimate the number of sign changes, but this occurs because of the discontinuities at the end of one 3-hour period and the beginning of the next period. Similarly, the 10- 
minute average and the linear model overestimate the 6.2 $\mathrm{MW} /$ minute actual interhour ramp rate for this day.

Because the interhour load trend defined by the 10-minute rolling-average method follows the dynamics too closely, the intrahour fluctuations defined by this method show relatively little variation, as measured by the absolute value and standard deviation of the fluctuations (right side of Table 1). At the other extreme, the linear fit to three hours of data follows the interhour load trend so poorly that the resultant intrahour fluctuation is greatly exaggerated. The 60 -minute rolling average and the cubic fit yield similar definitions for the shortterm fluctuations.

The top part of Fig. 2 shows the regression-model resuits from 6 a.m. to 9 a.m., and the bottom part shows the rollingaverage results. Our visual inspection of the data and alternative averaging approaches plus the statistics in Table 1 suggest that a cubic fit to the data or a 60 -minute rolling average perform well. That is, both methods follow the long-term load variations and do not follow the short-term tluctuations.

Table 1. Comparison of alternative methods to define interhour load trends ${ }^{a}$

\begin{tabular}{|c|c|c|c|c|}
\hline \multirow[b]{2}{*}{ Method } & \multicolumn{2}{|c|}{ Interhour trend } & \multicolumn{2}{|c|}{ Intrahour } \\
\hline & $\begin{array}{l}\text { Average of } \\
\text { absolute } \\
\text { values of } \\
\text { ramp rate } \\
\text { (MW/min) }\end{array}$ & $\begin{array}{c}\text { Sign } \\
\text { changes } \\
\text { per day }\end{array}$ & $\begin{array}{l}\text { Average } \\
\text { of } \\
\text { absolute } \\
\text { values } \\
\text { (MW) }\end{array}$ & $\begin{array}{c}\text { Standard } \\
\text { deviation } \\
\text { (MW) }\end{array}$ \\
\hline \multicolumn{5}{|c|}{ Rolling average } \\
\hline $\begin{array}{l}10- \\
\text { minute }\end{array}$ & 9.7 & 159 & 27 & 21 \\
\hline $\begin{array}{l}30- \\
\text { minute }\end{array}$ & 7.1 & 86 & 47 & 38 \\
\hline $\begin{array}{l}60- \\
\text { minute }\end{array}$ & 6.4 & 54 & 64 & 52 \\
\hline \multicolumn{5}{|c|}{ Regression model } \\
\hline Cubic & 7.2 & 16 & 61 & 48 \\
\hline Quadratic & 7.8 & 12 & 90 & 67 \\
\hline Linear & 8.3 & 6 & 132 & 101 \\
\hline
\end{tabular}

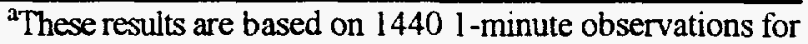
a. 24-hour period in December 1995, with separate fits to the eight 3-hour periods from midnight to midnight.

${ }^{b}$ All six fits to the data resulted in sign changes for the intrahour fluctuations of 29 to 32 times/hour and averages of the absolute value of ramp rates of 19 to $22 \mathrm{MW} /$ minute.

Table 2 compares the characteristics of inter- and intrahour load following. The intrahour results are based on 1-minute averages for this Midwestern utility for a single day in December 1995 (1440 observations in all), calculated as the deviations from cubic fits to the load data. Two sets of interhour results are shown, one for the same day (24 hourly observations) as that used to calculate intrahour load resuits and one for the entire year ( 8760 observations).

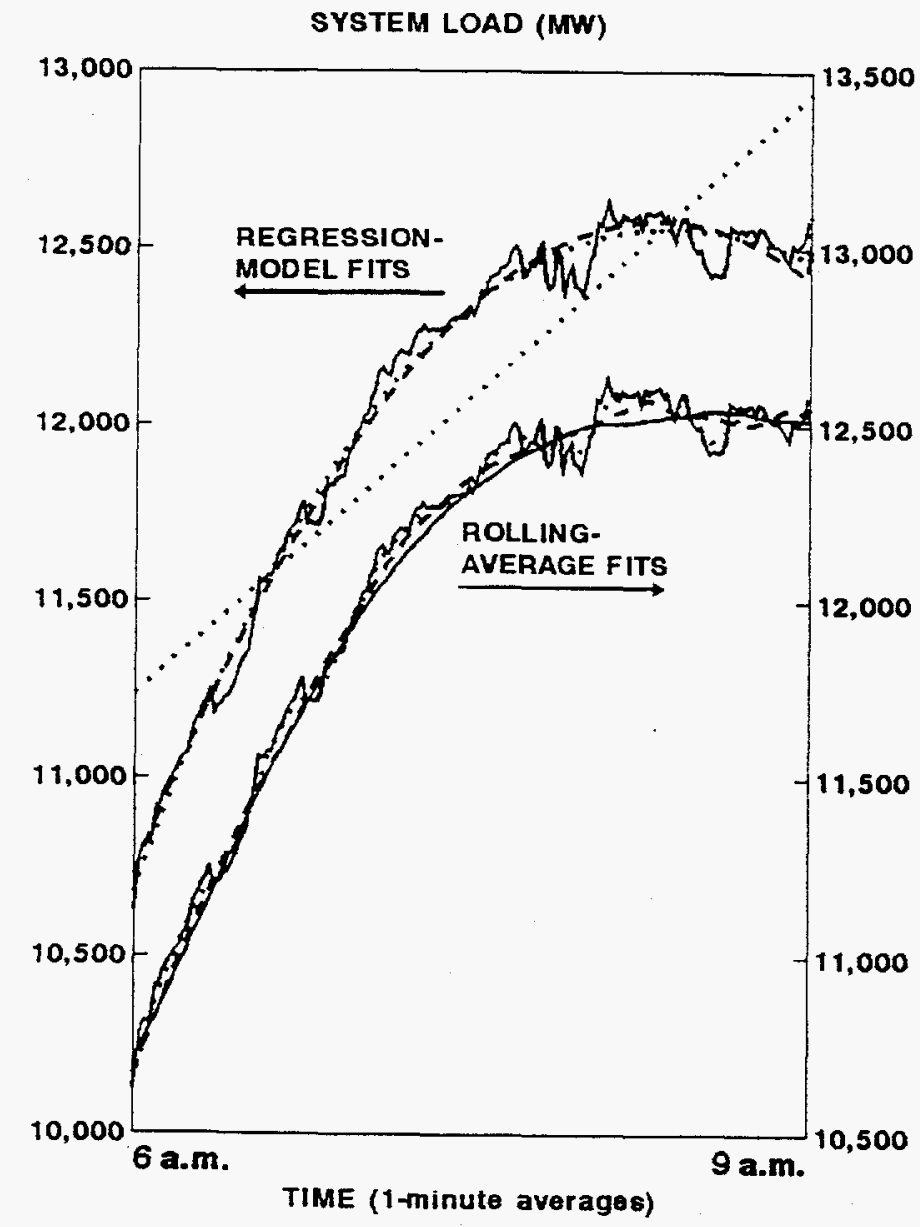

Fig. 2. One-minute loads and several regression-model (top) and rolling-average (bottom) fits to the data from 6 to 9 a.m. for a winter day.

Over the course of a year, loads range from a low of 5900 MW (early morning hours during the spring and fall) to almost $18,000 \mathrm{MW}$ (summer afternoon hours). The hourly load changes reach more than $1500 \mathrm{MW} /$ hour, with the increases typically occurring between 6 and 7 a.m. and the decreases occurring in the summer between 11 p.m. and midnight. 
Table 2. Comparison of intra- and interhour load following

\begin{tabular}{|c|c|c|c|}
\hline \multirow[t]{2}{*}{-} & \multirow{2}{*}{$\begin{array}{c}\text { Intrahour } \\
\text { 24-hour day }\end{array}$} & \multicolumn{2}{|c|}{ Interhour } \\
\hline & & 24-hour day ${ }^{2}$ & 8760-hour year ${ }^{b}$ \\
\hline \multicolumn{4}{|l|}{ Magnitude of swings (MW) } \\
\hline Maximum & \pm 170 & $\pm 2,100$ & $\pm 6,000$ \\
\hline Average & $0\left(48^{\circ}\right)$ & 11,700 & 9,700 \\
\hline Standard deviation & 61 & 1,400 & 2,000 \\
\hline \multicolumn{4}{|l|}{ Rate of change ( $\mathrm{MW} /$ minute) } \\
\hline Maximum & \pm 125 & \pm 20 & \pm 26 \\
\hline Average of absolute values ${ }^{\mathfrak{c}}$ & 20 & 6.2 & 5.7 \\
\hline Number of sign changes per hour & 31 & 0.27 & 0.19 \\
\hline
\end{tabular}

${ }^{a}$ These results are for a single day in December 1995. The intrahour results are based on 1-minute averages. The interhour results are based on hourly averages.

${ }^{b}$ These results are for the entire year 1994.

${ }^{c}$ The average of the intrahour load swings is, by definition, zero.

Aggregate intra- and interhour load following differ in three important ways:

- The magnitude (in $\mathrm{MW}$ ) of load swings is much greater for interhour changes than for intrahour changes; the difference is a factor of 15 to 40 .

- The speed of changes (MW/minute) is much greater for intrahour changes than for interhour changes; the difference is a factor of 3 to 5 .

- The frequency of change in direction (i.e., the sign on the ramp rate) is much greater for intrahour changes than for interhour changes; the difference is roughly a factor of 100

These differences in the amount and speed of load changes affect the types of generating units needed to respond to these two kinds of load changes. Generators used to provide regulating service must respond quickly to frequent, but small, load changes. On the other hand, generators used to provide load-following service must respond to large, but slowly changing, loads.

\section{INTRAHOUR LOAD SWINGS}

As Fig. 1 shows, overall load declined from 10,100 MW at midnight to about $9300 \mathrm{MW}$ at 3 a.m., an $8 \%$ (800-MW) drop, based on a cubic fit to these data. The 1 -minute load data fluctuate around this trendline with a maximum 1-minute change of $170 \mathrm{MW}$ in either direction and a standard deviation of $67 \mathrm{MW}$. Ignoring the direction of change, loads fluctuate an average of $55 \mathrm{MW}$ at an average rate of $21 \mathrm{MW} /$ minute during this 3-hour period. The load fluctuations change sign (e.g, from increasing to decreasing) $54 \%$ of the time; in other words, roughly once every other minute loads change from decreasing to increasing or from increasing to decreasing.

Figure 3 shows the 10-second "speeds" for load and generation from midnight to 1 a.m. Loads move up or down at an average rate of $74 \mathrm{MW} /$ minute and change direction more than 200 times per hour.

Table 3 shows how the range, average, and standard deviation of the load fluctuations and their speeds change when the time-averaging period is increased from 10 seconds to 2 minutes. While the measures of magnitude drop by 4 to $15 \%$ in going from the 10 -second to the 2-minute level, the measures of rate-of-change drop dramatically, by 80 to $95 \%$. Thus, the standard deviation and average for the magnitude of load swings are nearly independent of the time-averaging period used to define intrahour load swings. (We know of two utilities that observed near-constant standard deviations in their analyses of intrahour load fluctuations.) However, the rate-of-change measures are strongly dependent on the averaging period; the longer the averaging period, the slower the rate of change and the fewer the direction changes.

An increase in generator/load imbalance of about $60 \mathrm{MW}$ (the difference in magnitude between the maximum swings at 10 -second vs 120-second intervals) would increase the frequency deviation in the Eastern Interconnection by only $0.0015 \mathrm{~Hz}$. Even in the Western Interconnection or the Electric Reliability Council of Texas, a $60-\mathrm{MW}$ generator/load imbalance would affect frequency by 0.004 or $0.01 \mathrm{~Hz}$, respectively. 
Table 3.

Effects on intrahour load swings from midnight to $3 \mathrm{am}$. of increasing the time over which load is averaged

\begin{tabular}{|c|c|c|c|c|c|}
\hline \multirow{2}{*}{$\begin{array}{l}\text { Averaging period } \\
\text { (seconds) }\end{array}$} & \multicolumn{3}{|c|}{ Magnitude of swings (MW) } & \multicolumn{2}{|c|}{ Rate of change (MW/minute) } \\
\hline & Maximum & $\begin{array}{c}\text { Average of } \\
\text { absolute values }\end{array}$ & $\begin{array}{l}\text { Standard } \\
\text { deviation }\end{array}$ & $\begin{array}{c}\text { Average of } \\
\text { absolute values }\end{array}$ & $\begin{array}{c}\text { Sign changes per } \\
\text { hour }\end{array}$ \\
\hline 10 & \pm 186 & 57 & 69 & 74 & 205 \\
\hline 30 & \pm 178 & 56 & 68 & 31 & 55 \\
\hline 60 & \pm 166 & 55 & 67 & 21 & 31 \\
\hline 90 & \pm 160 & 54 & 66 & 17 & 14 \\
\hline 120 & \pm 155 & 53 & 66 & 15 & 11 \\
\hline
\end{tabular}

\section{0-SECOND FLUCTUATIONS (MW/minute)}

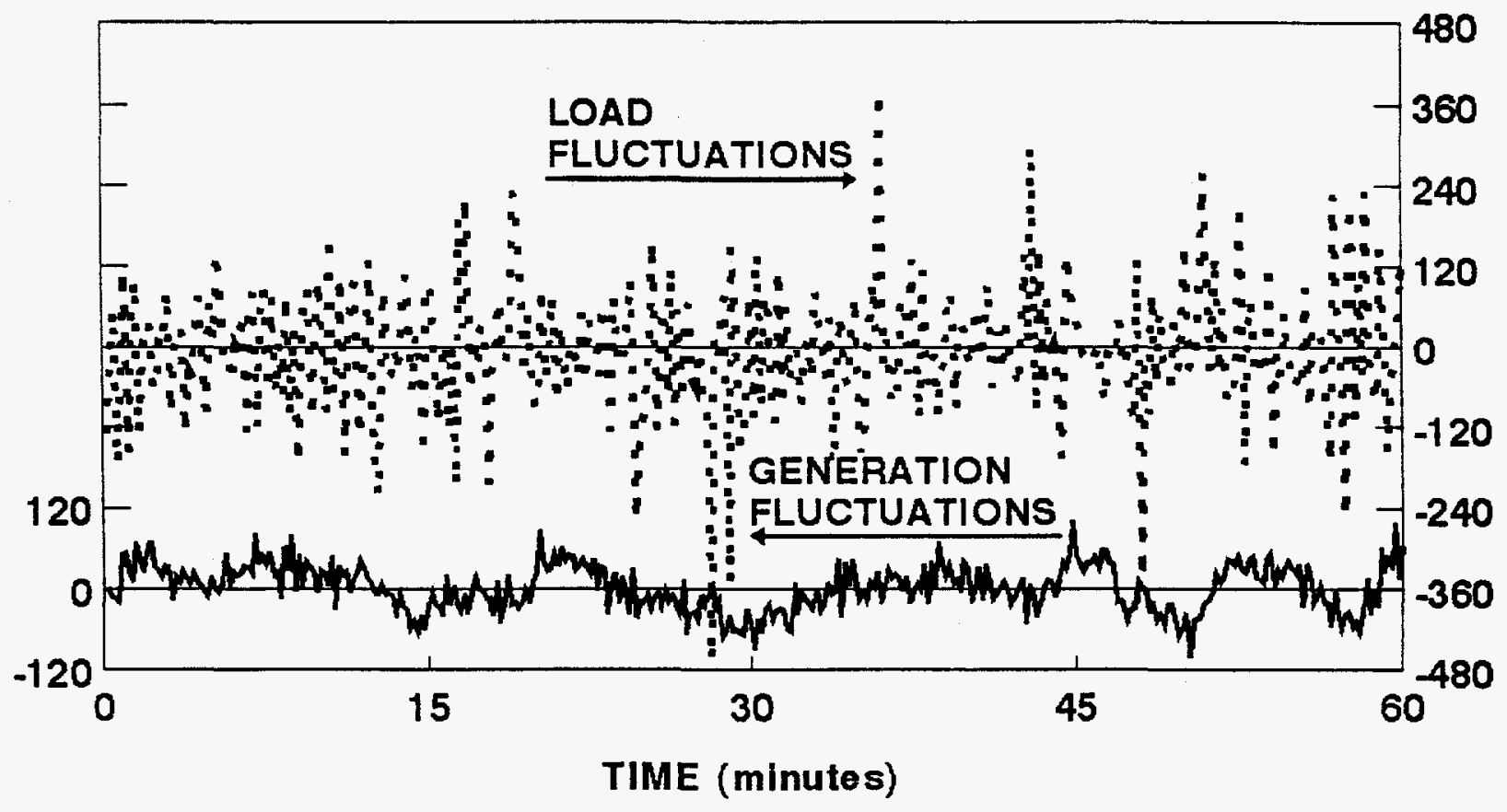

Fig. 3. Fluctuations in load and generation (measured at 10-second intervals) from midnight to 1 a.m.

The frequency-response characteristic is $4000 \mathrm{MW} / 0.1 \mathrm{~Hz}$ in the Eastern Interconnection, $1500 \mathrm{MW} / 0.1 \mathrm{~Hz}$ in the Western Interconnection, and $625 \mathrm{MW} / 0.1 \mathrm{~Hz}$ in the Electric Reliability Council of Texas [6]. The very small frequency deviations associated with a decision to ignore 10 -second fluctuations and the likelihood that 10 -second load fluctuations across utilities are uncorrelated suggests that control-area operators could safely ignore these high-frequency fluctuations.

\section{CONCLUSIONS}

Using data on loads from a large Midwestern control area, we examined several characteristics of load following. First, we used various averaging methods (i.e., rolling averages and regression models) to identify and define the interhour trends in system load. We found that a simple cubic fit to several hours of 1-minute load data yields satisfactory definitions of inter-and intrahour dynamics.

Using these averaging methods, we identified the intrahour load fluctuations. We compared the characteristics of inter- vs intrahour load. The short-term fluctuations differ from the longterm load changes in three ways. First, the magnitude (MW) of interhour load changes is much greater than that of intrahour load fluctuations. Second, the intrahour fluctuations change much more rapidly (MW/minute). And third, the intrahour fluctuations change direction much more often than do the interhour load changes. 
Next, we examined intrahour load swings in detail, focusing on the magnitude of load swings (measured by the maximum load change, standard deviation, and average of absolute value) and the rate of change of load swings (measured by the average of absolute value of load change and the number of sign changes per hour). We analyzed the implications of alternative time-averaging periods, ranging from 10 seconds to 2 minutes. While the standard deviation and average of absolute values of the magnitude are nearly invariant with the timeaveraging period, the measures of rate of change are very sensitive to the averaging period.

The present analysis leads to the following thoughts on two issues that require further data and analysis. Additional research is required, we believe, because the results presented here are based on very limited data, primarily from one utility for only a day or two.

- What methods should be used to identify and define the hour-to-hour trends in system load (load following)? What criteria should be used in selecting a preferred method?

- What are the appropriate metrics to use in defining intrahour load following? Are the characteristics considered here-the magnitude of load changes (MW), the speed of load changes (MW/minute), and the number of direction changes-appropriate and sufficient? The metrics chosen must be practical, both for metering and billing purposes.

\section{REFERENCES}

[1] E. Hirst and B. Kirby 1996, Ancillary-Service Details: Regulation, Load Following and Generator Response, ORNL/CON-433, Oak Ridge National Laboratory, Oak Ridge, TN, September.
[2] U.S. Federal Energy Regulatory Commission 1996, Promoting Wholesale Competition Through Open Access Non-Discriminatory Transmission Services by Public Utilities; Recovery of Stranded Costs by Public Utilities and Transmitting Utilities, Final Rule, Docket Nos. RM95-8-000 and RM94-7-001, Order 888, Washington, DC, April 24.

[3] A. Sammut 1996, "Regulation," Interconnected Operations (Ancillary) Services: Workshop on Definitions and Requirements for Managing Unbundled IOS, Palm Beach Gardens, FL, June 19-20.

[4] P. Steitz 1996, "Load Following," Interconnected Operations (Ancillary) Services: Workshop on Definitions and Requirements for Managing Unbundled IOS, Palm Beach Gardens, FL, June 19-20.

[5] E. Hirst and B. Kirby 1996, Electric-Power Ancillary Services, ORNL/CON-426, Oak Ridge National Laboratory, Oak Ridge, TN, February.

[6] D. Benjamin 1996, Interconnected Operations Services: A Technical Discussion, draft, North American Electric Reliability Council, Princeton, NJ, July.

Eric Hirst and Brendan Kirby are senior researchers at Oak Ridge National Laboratory. Their research focuses on issues related to electric-industry restructuring, especially as it relates to ancillary services. Hirst holds a Ph.D. in mechanical engineering from Stanford University. Kirby holds an MS degree in electrical engineering from Carnegie Mellon University. 